\title{
Pneumocystis carinii: Inhibition of Lung Cell Growth Mediated by Parasite Attachment
}

\author{
A. H. Limper and W. J. Martin II \\ Division of Thoracic Diseases, Department of Internal Medicine, Mayo Clinic, Rochester, Minnesota 55905
}

\begin{abstract}
Pneumocystis carinii pneumonia is a significant cause of mortality in immunocompromised patients. Current concepts suggest that attachment of $P$. carinii to alveolar epithelium is required for development of pneumonia. We examined the mechanism of $P$. carinii adherence to cultured A549 cells, a permanent cell line derived from human alveolar epithelium. $P$. carinii adherence was quantified by measuring attachment of ${ }^{51}$ Cr-labeled $P$. carinii to cultured A549 cells. After 8 h of incubation, $37.4 \pm 4.2 \%$ of $P$. carinii were adherent to $A 549$ cells. In the presence of agents known to impair cytoskeletal function, including $10^{-5} \mathrm{M}$ cytochalasin $\mathrm{B}, 1^{-5} \mathrm{M}$ colchicine, and $10^{-5} \mathrm{M}$ trimethylcolchicinic acid (TMCA), adherence was decreased from $57.4 \pm 4.2 \%$ to $9.3 \pm 3.4 \%, 12.5 \pm 3.6 \%$, and $21.5 \pm 3.6 \%$, respectively $(P<0.01$, all comparisons). Secondly, we examined the effect of $P$. carinii on the function of A549 cells. $P$. carinii resulted in significant impairment of A549 cell growth, indicating $P$. carinii adversely affected the function of target lung cells. A $P$. carinii :A549 cell ratio of 50:1 resulted in 43.5 $\pm 2.9 \%$ inhibition of $A 549$ cell growth $(P<0.001)$. Additionally, TMCA, which significantly prevented attachment of $P$. carinii, reversed the impairment of A549 cell growth. These data demonstrate that $\boldsymbol{P}$. carinii attachment to cultured lung cells can be quantified, is dependent on intact cytoskeletal function and is necessary for impairment of lung cell replication. (J. Clin. Invest. 1990. 85:391-396.) Pneumocystis carinii - pneumonia $\cdot$ parasite adherence $\bullet$ cytochalasin $B \cdot$ colchicine
\end{abstract}

\section{Introduction}

Pneumocystis carinii pneumonia is a frequent life-threatening complication of immune deficiency. Current concepts suggest growth of $P$. carinii organisms requires attachment of $P$. carinii trophozoites to the alveolar epithelial cells of the lung (1-7). $P$. carinii organisms appear to preferentially attach to type I alveolar epithelial cells, although small numbers may attach to the surface of type II alveolar epithelial cells $(1,4-7)$. There is no evidence to suggest that $P$. carinii enters the epithelial cell or has an intracellular phase in its life cycle; rather, the organisms remain on the surface of the cell. The mechanism of $P$. carinii attachment and how the lung cell is affected by this attachment is poorly understood.

Address reprint requests to Dr. Martin, Indiana University Medical Center, 1001 West Tenth Street, West Outpatient Building, Room 425, Indianapolis, IN 46202.

Received for publication 16 March 1989 and in revised form 18 August 1989.

J. Clin. Invest.

(C) The American Society for Clinical Investigation, Inc.

0021-9738/90/02/0391/06 \$2.00

Volume 85, February 1990, 391-396
Ultrastructural studies have provided important descriptive information regarding the attachment of $P$. carinii to alveolar epithelial cells (1-7). Although earlier reports suggested that $P$. carinii use specialized "filopodia" as organelles of attachment $(8,9)$, more recent studies suggest $P$. carinii attachment is not mediated by specialized structures (3-5); rather, attachment occurs as a result of close apposition (not fusion) of the cell membranes of $P$. carinii to the alveolar epithelial cell (3-6).

The study of $P$. carinii attachment to lung cells has been limited by the absence of an appropriate model that permits quantification of attachment and isolation of variables thought to be important in the attachment process. Our study includes the development of a novel method to quantify $P$. carinii attachment and suggests that $P$. carinii requires intact cytoskeletal function to adhere to target lung cells. Furthermore, $P$. carinii appears to adversely affect target cell function by impairing lung cell replication. This $P$. carinii-mediated impairment of lung cell growth requires attachment of the organism to the target cell surface since agents that prevent attachment also reverse this adverse effect on the target cell population.

\section{Methods}

P. carinii isolation and purification. P. carinii pneumonia was induced in Harlan Sprague-Dawley rats by immunosuppression with dexamethasone as previously described by Hughes and co-workers (10). Female Harlan Sprague Dawley rats (250 g; Harlan Sprague Dawley, Inc., Indianapolis, IN) were housed in open cages in a clean but not sterile environment. Drinking water containing a mixture of dexamethasone $(2 \mathrm{mg} /$ liter $)$, tetracycline hydrochloride $(500 \mathrm{mg} /$ liter $)$, and nystatin (200,000 U/liter) was provided ad lib. Rats were maintained on a diet containing $8 \%$ protein in order to intensify the severity of $P$. carinii disease (Teklad Corp., Madison, WI) (11).

After $8 \mathrm{wk}$ of treatment, rats exhibited evidence of respiratory distress, wasting, and hair loss, and were killed by lethal injection with $26 \%$ pentobarbital intraperitoneally. After aseptically opening the thorax, rats were exsanguinated and the lungs perfused with HBSS, without calcium or magnesium, containing $0.6 \mathrm{mM}$ EDTA, penicillin $(100 \mu \mathrm{g} / \mathrm{ml})$, gentamicin $(4 \mu \mathrm{g} / \mathrm{ml})$, and amphotericin B $(0.5 \mu \mathrm{g} / \mathrm{ml})$. Whole lung lavage was performed with sequential $10-\mathrm{ml}$ aliquots of HBSS with immediate return of up to $50 \mathrm{ml}$ of instilled fluid.

$P$. carinii organisms were isolated and purified by differential centrifugation adapted from the method described by Masur (12). Pooled lavage fluid (typically $45 \mathrm{ml}$ ) was centrifuged $(800 \mathrm{~g} \times 10 \mathrm{~min})$ and $P$. carinii cysts were identified in the inflammatory cell pellets using a modified Grocott methenamine silver stain (13). The turbid supernatants containing predominantly $P$. carinii organisms were centrifuged $(1,400 \mathrm{~g} \times 30 \mathrm{~min})$, the pellets resuspended in $1 \mathrm{ml}$ of HBSS, and $P$. carinii organisms were quantified by the method of Bartlett et al. (14). Duplicate $10-\mu 1$ aliquots of this suspension were directly spotted onto glass slides, air dried, and stained with Diff-Quik (Harleco, Dade Diagnostics, Aquada, Puerto Rico). Each drop occupied $\sim 1 \mathrm{~cm}^{2}$ on the slide, and the number of $P$. carinii trophozoites in 10 oil immersion fields was determined from each spot. The total number of $P$. carinii was calculated using the formula: $P$. carinii $/ \mathrm{ml}=(P$. carinii $/$ field $)$ 
$\times($ No. of fields/drop $) \times\left(10^{2}\right)$. Using the above method, average yield was $(9.01 \pm 0.41) \times 10^{6}$ purified $P$. carinii organisms from each rat lavaged. Further, $P$. carinii organisms represented $96.5 \pm 0.5 \%$ of the cellular differential, with the remainder representing mostly nonviable inflammatory cells. Occasional rats had evidence of significant bacterial contamination noted on smears of the lavage, and these were discarded. Despite occasional evidence of other microorganisms on smears of the lavages, microbiologic evaluation of selected rat lavage isolates failed to culture any known pathogenic bacteria, fungi, or virus.

$P$. carinii adherence assays. Freshly isolated $P$. carinii $\left(24 \times 10^{6}\right.$ organisms) were incubated for $18 \mathrm{~h}$ in $1 \mathrm{ml}$ of Dulbecco's modified Eagle's medium (Whittaker M. A. Bioproducts, Walkersville, MD) containing $20 \%$ heat-inactivated fetal calf serum, penicillin $(10 \mu \mathrm{g} / \mathrm{ml})$, gentamicin $(4 \mu \mathrm{g} / \mathrm{ml})$, amphotericin $(0.5 \mu \mathrm{g} / \mathrm{ml})$ and $50 \mu \mathrm{Ci}{ }^{51} \mathrm{Cr} / \mathrm{ml}$ $(679 \mathrm{mCi} / \mathrm{mg}$, New England Nuclear, Boston, MA). This suspension was washed four times with medium to remove unincorporated ${ }^{51} \mathrm{Cr}$ and adjusted to a concentration of $2.0 \times 10^{6} P$. carinii per ml. Two million ${ }^{51} \mathrm{Cr}$-labeled $P$. carinii were incubated with confluent monolayers of A549 cells (American Type Culture Collection, Rockville, MD) grown in 24-well plates using DME containing $10 \%$ heat-inactivated fetal calf serum and penicillin, gentamicin and amphotericin as noted above. After centrifugation onto the monolayers $(1,400 \mathrm{~g} \times 5$ $\mathrm{min}),{ }^{51} \mathrm{Cr}$-labeled $P$. carinii organisms were incubated with the A549 cell monolayers for $0,2,4$, and $8 \mathrm{~h}$. After incubation, media were removed and A549 cells washed three times with HBSS to remove any unattached ${ }^{51} \mathrm{Cr}$-labeled $P$. carinii organisms. Adherence of $P$. carinii was defined as follows: $\%$ adherence $=(A / A+B) \times 100 \%$, where $A$ $=\mathrm{dpm}$ of ${ }^{51} \mathrm{Cr}$ associated with the A549 cell monolayer and $\mathrm{B}=\mathrm{dpm}$ of ${ }^{51} \mathrm{Cr}$-labeled $P$. carinii not adherent to the cellular monolayer.

To provide morphologic confirmation of $P$. carinii adherence to cultured A549 cells, $2 \times 10^{6} P$. carinii. were incubated with confluent monolayers of A549 cells grown on sterile plastic coverslips (Thermanox Tissue Culture Slips; Miles Laboratories, Inc., Naperville, IL) as described above. After incubating, the coverslips were removed, washed with HBSS and fixed in Trump's fixative containing $1 \%$ glutaraldehyde and $4 \%$ formaldehyde in $0.1 . \mathrm{M} \mathrm{NaPO}_{4}$ buffer at $\mathrm{pH}=7.20$ for $2 \mathrm{~h}$. Scanning electron microscopy (SEM) was performed using an ETEC Autoscan microscope (Perkin-Elmer, Norwalk, CT).

To assess the importance of parasite cytoskeletal function on adherence, additional assays were conducted in the presence and absence of $10^{-6}-10^{-5} \mathrm{M}$ concentrations of cytochalasin B (Sigma Chemical Co., St. Louis, MO), colchicine (Eli Lilly Co., Indianapolis, IN), or trimethylcolchicinic acid (TMCA) ${ }^{1}$ (Sigma Chemical Co.) for $8 \mathrm{~h}$, and the \% adherence of ${ }^{51} \mathrm{Cr}$-labeled $P$. carinii was determined as noted above.

To verify that cytochalasin B, colchicine, and TMCA did not adversely affect $P$. carinii viability, ${ }^{51} \mathrm{Cr}$ release (measure of cytotoxicity) and $\left[{ }^{3} \mathrm{H}\right]$ leucine incorporation (measure of protein synthesis) were measured. The percent release of ${ }^{51} \mathrm{Cr}(\% \mathrm{R})$ from labeled $P$. carinii during $8 \mathrm{~h}$ of incubation in the presence and absence of $10^{-5} \mathrm{M}$ cytochalasin $B$, colchicine, or TMCA was determined as follows: \% $R$ $=(A / A+B) \times 100 \%$ where $A=d p m$ of ${ }^{51} \mathrm{Cr}$ released into the medium and $B=\mathrm{dpm}$ of ${ }^{51} \mathrm{Cr}$ associated with $P$. carinii. To determine the effect of these agents on protein synthesis, $2 \times 10^{6} P$. carinii organisms were incubated with $\left[{ }^{3} \mathrm{H}\right]$ leucine $(75 \mu \mathrm{Ci} / \mathrm{ml})(140 \mathrm{Ci} / \mathrm{mmol}$, New England Nuclear) for $8 \mathrm{~h}$ in the presence and absence of $1 \times 10^{-5}$ cytochalasin B, colchicine, or TMCA. After incubation, the $P$. carinii were washed free of medium and sonicated. The sonicate was precipitated in icecold $10 \%$ trichloroacetic acid and the precipitable protein measured by scintillation counting.

$A 549$ cell growth assay. The effect of $P$. carinii on the function of the A549 cells was measured by monitoring A549 cell replication. A549 lung cells were cultured in DME containing 10\% heat-inacti-

1. Abbreviations used in this paper: GI, growth impairment; TMCA, trimethylcolchicine. vated fetal calf serum, penicillin, gentamicin, and amphotericin B as noted previously. Confluent monolayers of A549 cells were grown in $25 \mathrm{~cm}^{2}$ tissue culture flasks (Corning Glass Works, Parkridge, IL), removed by brief treatment with Trypsin Versene $(1 \times)$ (Biofluids, Rockville, MD), and replated in fresh medium at a density of 30,000 cells per well in 6-well tissue culture plates (Nunc, Inc., Naperville, IL). After attachment of A549 cells to tissue culture plates ( $4 \mathrm{~h}$ ), medium was replaced with fresh medium containing appropriate numbers of $P$. carinii organisms. Wells containing A549 cells without $P$. carinii organisms served as controls. After $72 \mathrm{~h}$, the medium was removed and monolayers were washed thoroughly with three aliquots of HBSS. The A549 target cells were completely removed with Trypsin Versene (1X) and were enumerated by Coulter counter analysis (model ZF; Coulter Electronics, Inc., Hialeah, FL).

Impairment of target cell growth was expressed as a growth impairment (GI) index, as previously described (15), where $100 \%$ represents total inhibition of growth and $0 \%$ represents normal growth of A549 cells. The following formula was employed: GI Index $=$ [(A - B)/A] $\times 100 \%$, where $A=A 549$ cell count in control wells, and B $=$ A549 cell count in wells containing $P$. carinii.

Assessment of culture medium. To determine whether $P$. carinii consume excess media nutrients or release soluble growth inhibiting substances into the culture media, media incubated with A549 cells with or without $P$. carinii was assayed to determine its effect on further A549 cell growth. Media removed from A549 cell growth assays were filter sterilized using $0.45 \mu \mathrm{m}$ disk filters (Acrodisc; Gelman Sciences, Ann Arbor, MI) to remove $P$. carinii organisms, added to 6-well culture plates containing newly seeded A549 cells $(30,000$ cell/well) and incubated for $72 \mathrm{~h}$. A549 cells were then removed from the culture dishes and the GI indices determined as noted above.

Statistical methods. Data are expressed as mean \pm SEM. Differences between experimental and control data groups were assessed using Student's two-sample $t$ test for two-sided alternatives in which $P<0.05$ was defined as a statistically significant result.

\section{Results}

$P$. carinii adherence assays. $P$. carinii adherence to monolayer A549 cells was quantified using ${ }^{51} \mathrm{Cr}$-labeled $P$. carinii. Incubation of ${ }^{51} \mathrm{Cr}$-labeled $P$. carinii with A549 target cells for 2, 4, and $8 \mathrm{~h}$ (Fig. 1) resulted in $13.0 \pm 1.4 \%, 40.6 \pm 4.6 \%$, and $37.4 \pm 4.2 \%$ adherence, respectively, $(P<0.001$, latter two comparisons to control at $0 \mathrm{~h}$ ). Ultrastructural examination by SEM revealed $P$. carinii organisms to be adherent to the A549 cell monolayer with $P$. carinii typically attaching in clusters to one in every four or five monolayer cells (Fig. 2). When ${ }^{51} \mathrm{Cr}$ counts were detectable, adherent $P$. carinii were present; similarly, when no ${ }^{51} \mathrm{Cr}$ counts were detectable, no $P$. carinii organisms were visible by SEM. Thus, adherence of $P$. carinii to cultured A549 cells could be quantified using ${ }^{51} \mathrm{Cr}$-labeled organisms and occurred in a time-dependent fashion and appeared to reach a maximum between 4 and $8 \mathrm{~h}$.

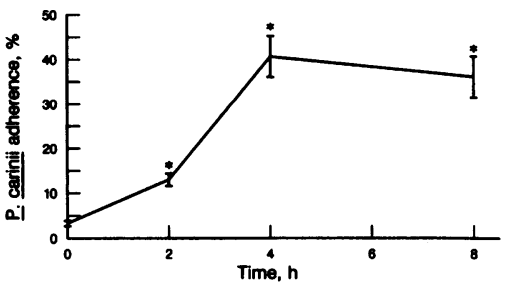

Figure 1. Time course of $P$. carinii adherence to $\mathrm{A} 549$ cells. The ${ }^{51} \mathrm{Cr}$ labeled $P$. carinii were incubated with A549 cell monolayers for 0,2 , 4 , and $8 \mathrm{~h}$. Data are expressed as percent adherence of $P$. carinii to A549 cell monolayers. *Denotes comparisons which were significantly different from controls $(P<0.05)$. Each data point represents six determinations and are expressed as mean \pm SEM. 

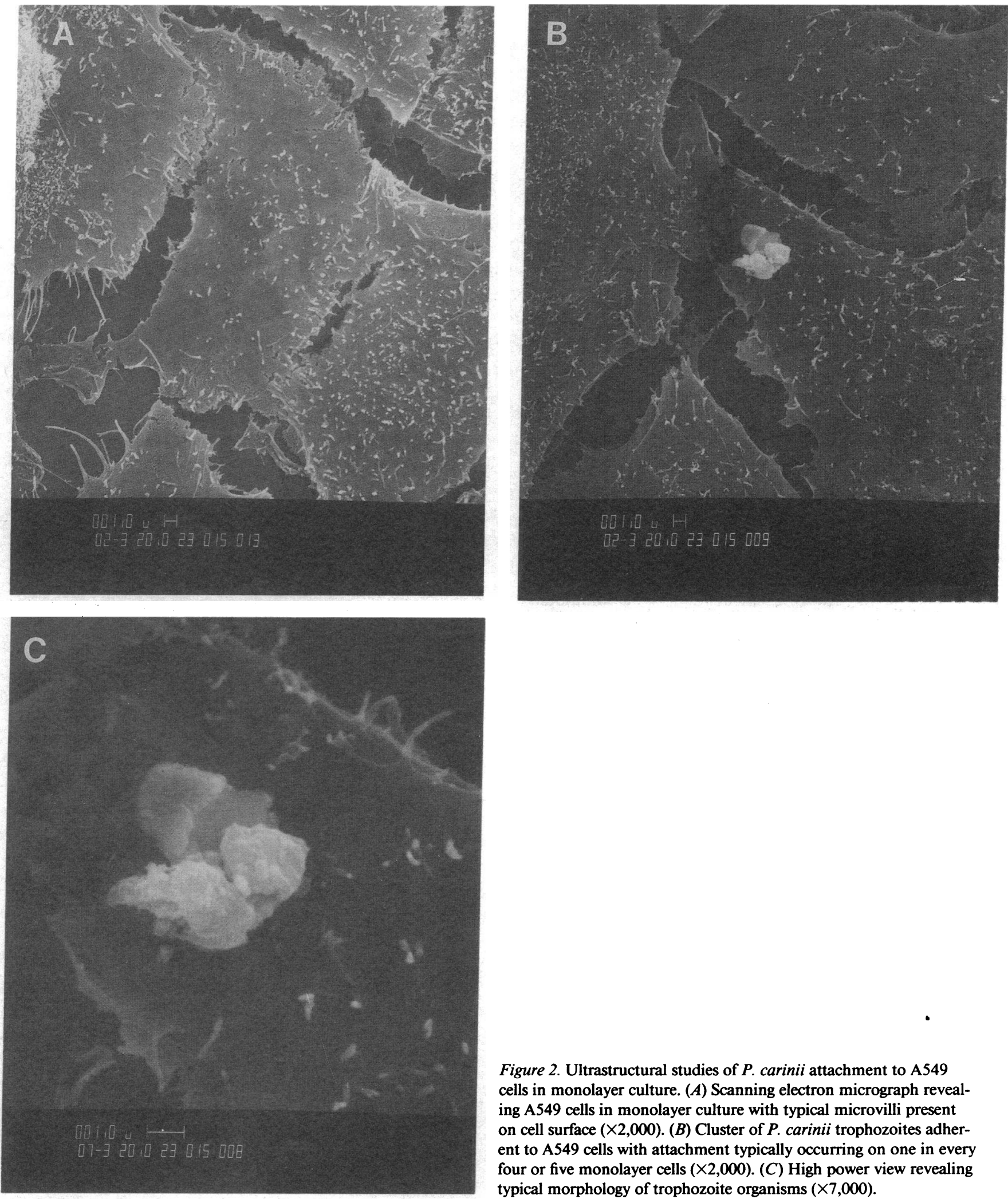

Role of cytoskeletal components in adhesion. To determine the need for intact cytoskeleton function in the adherence of $P$. carinii to target cells, assays were conducted in the presence and absence of the antimotility agents cytochalasin B, colchicine, or the colchicine derivative, TMCA (Fig. 3). The adher-
Figure 2. Ultrastructural studies of $P$. carinii attachment to A549 cells in monolayer culture. $(A)$ Scanning electron micrograph revealing A549 cells in monolayer culture with typical microvilli present on cell surface $(\times 2,000)$. (B) Cluster of $P$. carinii trophozoites adherent to A549 cells with attachment typically occurring on one in every four or five monolayer cells $(\times 2,000)$. $(C)$ High power view revealing typical morphology of trophozoite organisms $(\times 7,000)$.

ence of $P$. carinii to the A549 cell layer was reduced from a control value of $37.4 \pm 4.2 \%$ to $9.3 \pm 3.4 \%\left(10^{-5} \mathrm{M}\right.$ cytochalasin B), $12.5 \pm 3.6 \%\left(10^{-5} \mathrm{M}\right.$ colchicine), and $21.5 \pm 3.6 \%\left(10^{-5} \mathrm{M}\right.$ TMCA) $(P<0.01$, all comparisons). Further adherence assays were conducted using $P$. carinii or A549 cells with only a 1-h 


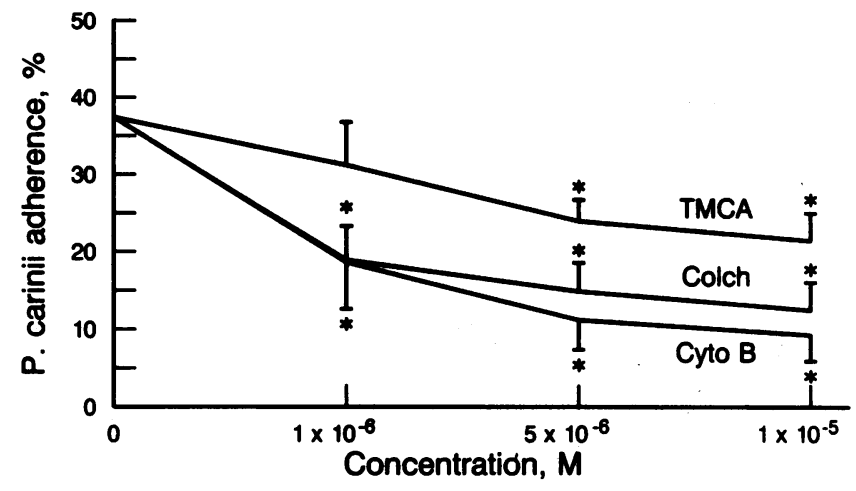

Figure 3. Reduction of $P$. carinii adherence to A549 lung cells by agents that impair cytoskeletal function. The ${ }^{51} \mathrm{Cr}$-labeled $P$. carinii were incubated with A549 cell monolayers for $8 \mathrm{~h}$. Data are expressed as percent adherence of $P$. carinii to A549 cells at 8 h. $P$. carinii containing media were treated with increasing concentrations of trimethylcolchicinic acid (TMCA), colchicine (colch), and cytochala$\sin B$ (cyto B). *Comparisons that are significantly different from controls $(P<0.05)$. Each data point represents six determinations and is expressed as mean \pm SEM.

preincubation of the cells with the antimotility agents at the same concentrations, followed by washing and incubating in the absence of the agents. Preincubation of the antimotility agents with either cell population failed to change adherence (data not shown), consistent with other studies which indicate the effects of these antimotility agents are "reversible" (16-18). Thus, agents that impair cytoskeletal function significantly reduced the adherence of the $P$. carinii organisms to A549 lung cells when present during the attachment process.

Additionally, the highest concentration of cytochalasin B, colchicine, and TMCA used $\left(10^{-5} \mathrm{M}\right)$, did not result in significantly greater release of ${ }^{51} \mathrm{Cr}$ from treated $P$. carinii compared with control organisms (control $=29.1 \pm 4.3 \%$; cytochalasin $B$ $=32.5 \pm 5.0 \%$; colchicine $=31.5 \pm 3.5 \%$; $\mathrm{TMCA}=30.0 \pm 3.5 \%$; $P>0.10$ all comparisons to control). Further, the incorporation of $\left[{ }^{3} \mathrm{H}\right]$ leucine into trichloroacetic acid precipitable protein by $P$. carinii organisms was not significantly altered in the presence of the drugs (control $=2,320 \pm 313 \mathrm{dpm}$; cytochalasin $\mathrm{B}=2,091 \pm 381 \mathrm{dpm}$; colchicine $=2,627 \pm 642 \mathrm{dpm}$; TMCA $2,174 \pm 150 ; P>0.10$ all comparisons to control). Thus, agents that impair cytoskeletal function of $P$. carinii organisms and impair adherence of the organism to A549 cells do not interfere with the apparent viability or functional status of $P$. carini $i$ organisms.

A549 target cell growth assay. Increasing concentrations of $P$. carinii organisms resulted in significant impairment of A549 cell growth as expressed by a dramatic increase in the GI index (Fig. 4). A P. carinii:A549 cell ratio of 1:10 resulted in a GI index of only $4.4 \pm 3.4 \%$ growth inhibition; whereas, at a ratio of $25: 1$, the GI index increased to $34.9 \pm 6.5 \%(P<0.005)$; and at $50: 1$, increased to $43.5 \pm 2.9 \%(P<0.001)$. No cytopathic effects were detectable in the target A549 cell population. Thus, the higher the number of $P$. carinii organisms the greater the impairment of A549 cell growth, indicating for the first time that $P$. carinii may seriously affect the normal function of target lung cell populations.

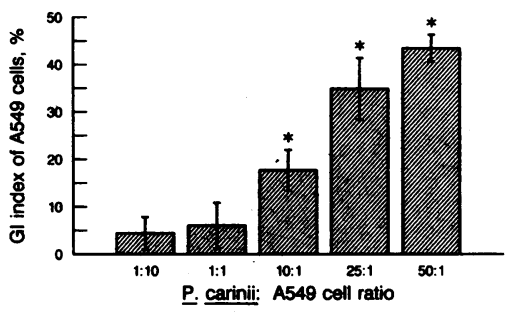

Figure 4. P. carinii-mediated impairment of A549 cell growth. A549 cell growth was quantified in the presence of increasing concentrations of $P$. carinii during a 72-h incubation. Data are expressed as a growth impairment index (GI index) where GI index of $0 \%$ represents normal A549 cell growth (control) and GI index of $100 \%$ indicates complete inhibition of A549 cell growth. *Comparisons that were significantly different from control $(P<0.05)$. Each data point represents six determinations and are expressed as mean \pm SEM.

Additionally, heat inactivation of $P$. carinii substantially reduced the growth-inhibiting properties of $P$. carinii on A549 cells. After heat inactivation $\left(56^{\circ} \mathrm{C} \times 1 \mathrm{~h}\right)$, heat killed $P$. carinii resulted in a growth inhibition of only $8.2 \pm 3.5 \%$ compared to $33.2 \pm 15.5 \%$ growth inhibition from control $P$. carinii $(P$ $<0.05$ ), indicating that viable $P$. carinii are necessary for significant growth inhibition.'

Effect of P. carinii treated culture media on A549 cell growth. Culture media incubated with A549 cells in the presence and absence of $P$. carinii was filter-sterilized to remove $P$. carinii organisms, and assayed to determine if $P$. carinii conditioned medium would impair A549 cell growth. Filter-sterilized media from incubations with A549 cells alone (controls) resulted in a GI index of $8.1 \pm 6.8 \%$; similarly, filter sterilized media from incubations with A549 cells and $P$. carinii organisms resulted in a $\mathrm{GI}$ index of $6.4 \pm 4.9 \%(P=0.8)$. Thus, there was no evidence of $P$. carinii-conditioned media adversely affecting A549 cell growth compared to control media. This suggests that $P$. carinii organisms do not impair A549 cell replication by consuming excess essential nutrients or releasing growth inhibiting toxins into the medium.

Role of adherence in growth impairment. To determine whether adherence of $P$. carinii is necessary for $P$. carinii to impair growth of A549 lung cells, the A549 cell growth assay was repeated with $P$. carinii in the presence and in the absence of TMCA (Fig. 5). TMCA was used because, unlike cytochalasin B and colchicine, it does not inhibit the growth of cultured cells (19). TMCA $\left(10^{-5} \mathrm{M}\right)$ reversed the effect of $P$. carinii on A549 cell growth with a reduction in the GI index from $56.2 \pm 2.9 \%$ (PC alone) to a GI index of $10.2 \pm 3.1 \%$ (PC with

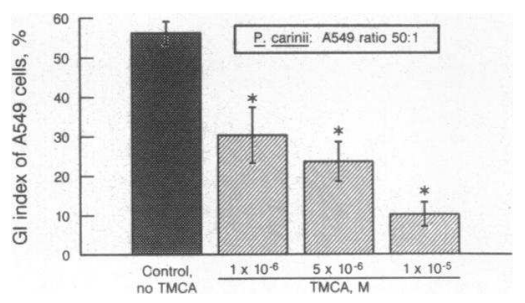

Figure 5. Reduction of P. carinii-induced impairment of A549 cell growth by trimethylcolchicinic acid (TMCA). A549 cell growth was quantified in the presence of $P$. carinii treated with increasing concentrations of TMCA during a 72-h incubation. Data are expressed as a growth impairment index (GI index). *Denotes comparisons that were significantly different from controls (no TMCA) $(P<0.05)$. Each data point represents six determinations and is expressed as mean \pm SEM. 
TMCA) $(P<0.001)$. Additionally, TMCA by itself had no adverse effect on the growth of A549 cells (data not shown). Thus, agents such as TMCA, which reduced the adherence of $P$. carinii to A549 lung cells, reversed the $P$. carinii-mediated impairment of A549 cell growth.

\section{Discussion}

$P$. carinii attachment to alveolar epithelial cells is critical to the development of $P$. carinii pneumonia (1-7). Attachment of microorganisms to host epithelial cells is necessary for the establishment of a variety of respiratory and nonrespiratory infections (20-24). Using a novel in vitro assay, $P$. carinii attachment to A549 lung cell monolayers can be quantified in a time-dependent fashion with maximal adherence occurring between 4 and $8 \mathrm{~h}$ of incubation.

Ultrastructural studies suggest that $P$. carinii adherence requires apposition and interdigitation of parasite cell membranes with those of alveolar epithelial cells $(5,7)$. The cytoskeleton of $P$. carinii is undoubtedly essential to the process of adherence. Recent ultrastructural studies by Itatani and Marshall demonstrate the presence of filamentous and microtubular structures extending into the pseudopodia of $P$. carinii trophozoites (7). Our studies indicate that agents that impair cytoskeletal function such as cytochalasin B, colchicine, and TMCA significantly reduce $P$. carinii adherence to target lung cells; however, these agents may reduce adherence of $P$. carinii by impairing cytoskeletal function in either the $P$. carinii or target cell populations. Since cytochalasin B inhibits actin filament polymerization and colchicine impairs cytoskeletal function by binding to tubulin (25-28), it is likely that $P$. carinii adheres to alveolar epithelial cells by mechanisms dependent on the functional integrity of both actin filaments and microtubule components.

Additionally, $P$. carinii adherence to alveolar epithelial cells adversely affects the normal functioning of lung cells. Ultrastructural studies of $P$. carinii pneumonia demonstrate vacuolization and degeneration of alveolar epithelial cells during $P$. carinii infection $(1,4)$. Our investigation further documents the ability of $P$. carinii to impair lung cell function by interfering with lung cell replication. If $P$. carinii attachment to alveolar epithelial cells in vivo inhibits cell division, this may significantly impair the normal repair mechanisms operative in the lung during $P$. carinii pneumonia.

Furthermore, our study suggests that the $P$. carinii mediated impairment of lung cell growth requires adherence of $P$. carinii to target cells. TMCA, an agent that does not impair cell division (19), significantly reduced $P$. carinii adherence to lung cells and reversed the effect of $P$. carinii on lung cell growth. It is possible such agents may have therapeutic potential in $P$. carinii pneumonia by directly reversing the toxic effect of $P$. carinii organisms on alveolar epithelial cells. Additionally, by interfering with the normal parasite life-cycle, these agents may also prevent the further growth of $P$. carinii organisms. Clearly, substantial additional testing would be required before any therapeutic application of this experimental data in human subjects.

Although $P$. carinii attachment to target cells is required, the mechanism of $P$. carinii-mediated impairment of cell growth is unknown. $P$. carinii-conditioned medium fails to confer growth impairment of cultured lung cells suggesting that the parasites do not consume excess essential nutrients nor release stable growth impairing products into the culture medium. Further study of this $P$. carinii-mediated toxicity may provide important insights into the host-parasite interaction and improve our understanding of mechanisms operative in the disease process.

\section{Acknowledgments}

This work was supported by National Institutes of Health grant HL/AI 43524.

\section{References}

1. Lanken, P. N., M. Minda, G. G. Pietra, and A. P. Fishman. 1980. Alveolar response to experimental Pneumocystis carinii pneumonia in the rat. Am. J. Pathol. 99:561-578.

2. Murphy, M. J., L. L. Pifer, and W. T. Hughes. 1977. Pneumocystis carinii in vitro: a study by scanning electron microscopy. Am. J. Pathol. 86:387-394.

3. Yoneda, K., and P. D. Walzer. 1983. Attachment of Pneumocystis carinii to type I alveolar epithelial cells by freeze-fracture electron microscopy. Infect. Immun. 40:812-815.

4. Henshaw, N. G., J. L. Carson, and A. M. Collier. 1985. Ultrastructural observation of Pneumocystis carinii attachment to rat lung. J. Infect. Dis. 151:181-186.

5. Long, E. G., J. S. Smith, and J. L. Meier. 1986. Attachment of Pneumocystis carinii to rat pneumocytes. Lab. Invest. 54:609-615.

6. Walzer, P. D. 1986. Attachment of microbes to host cells: relevance of Pneumocystis carinii. Lab. Invest. 54:589-592.

7. Itatani, C. A., and J. Marshall. 1988. Ultrastructural morphology and staining characteristics of Pneumocystis carinii in situ and from bronchoalveolar lavage. J. Parasitol. 74:700-712.

8. Hamm, E. K., S. D. Greensburg, R. C. Reynolds, and D. B. Singer. 1971. Ultrastructure of Pneumocystis carinii. Exp. Mol. Pathol. 14:362-372.

9. Vavra, J., and K. Kucera. 1970. Pneumocystis carinii Delanoë, its ultrastructure and ultrastructural affinities. J. Protozool. 17:463483.

10. Hughes, W. T., P. C. McNabb, T. D. Makres, and S. Feldman. 1974. Efficacy of trimethoprim and sulfamethoxazole in the prevention and treatment of Pneumocystis carinii pneumonitis. Antimicrobiol. Agents Chemother. 5:289-293.

11. Walzer, P. D., M. LaBine, and T. J. Redington. 1984. Predisposing factors in Pneumocystis carinii pneumonia: effects of tetracycline, protein malnutrition, and corticosteroids on hosts. Infect. Immun. 46:747-753.

12. Masur, H. 1984. Interactions between Pneumocystis carinii and phagocytic cells. In Pneumocystis carinii Pneumonia. L. S. Young, editor. Marcel Dekker, New York. 77-95.

13. Mahan, C. T., and G. E. Sale. 1978. Rapid methenamine silver stain for Pneumocystis and fungi. Arch. Pathol. Lab. Med. 102:351352.

14. Bartlett, M. S., P. A. Vervanac, and J. W. Smith. 1979. Cultivation of Pneumocystis carinii with WI-38 cells. J. Clin. Microbiol. 10:796-799.

15. Martin, W. J., II, and D. L. Kachel. 1989. Oxygen mediated impairment of human endothelial cell growth. Evidence for a specific threshold of toxicity. J. Lab. Clin. Med. 113:413-421.

16. Tilney, L. G. 1968. Studies on the microtubules in heliozoa. $J$. Cell. Sci. 3:549-562.

17. Yamada, K. M., B. S. Spooner, and N. K. Wessells. 1970. Axon growth: roles of microfilaments and microtubules. Proc. Nat. Acad. Sci. USA. 66:1206-1212. 
18. Goldman, R. D. 1972. The effects of cytochalasin B on the microfilaments of baby hamster kidney (BHK-21) cells. J. Cell. Biol. 52:246-254.

19. Wallace, S. L. 1975. Colchicine and new antiinflammatory drugs for the treatment of acute gout. Arthritis Rheum. 18:847-851.

20. Higuchi, J. H., and W. G. Johanson. 1980. The relationship between adherence of Pseudomonas aeruginosa to upper respiratory cells in vitro and susceptibility to colonization in vivo. J. Lab. Clin. Med. 95(5):698-705.

21. Niederman, M. S., W. W. Merrill, R. D. Ferranti, K. M. Pagano, L. B. Palmer, and H. Y. Reynolds. 1984. Nutritional status and bacterial binding in the respiratory tract in patients with chronic tracheostomy. Ann. Intern. Med. 100:798-800.

22. Niederman, M. S., R. D. Ferranti, A. Zeigler, W. W. Merrill, and H. Y. Reynolds. 1984. Respiratory infection complicating longterm tracheostomy: the implication of persistant gram-negative tracheobronchial colonization. Chest. 85(1):39-44.

23. Johanson, W. G., J. H. Higuchi, T. R. Chandhuri, and D. E.
Woods. 1980. Bacterial adherence to epithelial cells in bacillary colonization of the respiratory tract. Am. Rev. Respir. Dis. 121:55-63.

24. Schaeffer, A. J., J. M. Jones, and D. K. Dunn. 1981. Association of in vitro Escherichia coli adherence to vaginal and buccal epithelial cells with susceptibility of women to recurrent urinary tract infections. N. Engl. J. Med. 304:1062-1066.

25. Malech, H. L., R. K. Root, and J. I. Gallin. 1977. Structural analysis of human neutrophil migration. J. Cell Biol. 75:666-693.

26. Zakhire, B., and H. L. Malech. 1980. The effect of colchicine and vinblastine on the chemotactic response of human monocytes. $J$. Immunol. 125:2143-2153.

27. Valberg, P. A., J. D. Brain, and D. Kane. 1981. Effects of colchicine or cytochalasin B on pulmonary macrophage endocytosis in vivo. J. Appl. Physiol. 50:621-629.

28. Davies, P., and A. C. Allison. 1978. Effects of cytochalasin B on endocytosis and exocytosis. In Cytochalasins: Biochemical and Cell Biological Aspects. S. W. Tanenbaum, editor. North-Holland Publishing Co., New York. 143-160. 